\title{
EDITORIAL
}

\section{Geriatric Medicine : Bangladesh Perspective}

Ageing is a natural phenomenon which cannot be stopped or altered. From the dawn of civilization man is feared of being old. There is a German proverb, 'Old age is a disease that you die from'. In fact elderly suffer from variety of diseases which make them feeble, dependant and even bed bound. This is why, every human being wants to get rid of old age but this is inevitable.

From the era of ancient medicine, physicians tried their best to alleviate the sufferings of elderly but only a few people reached their maximum due to early death by diseases and war. When modern medicine evolved the average life span of human increased with time. This demographic transition started slowly but got it's pace very soon. Now $11 \%$ of the world population is of 65 years of age or over. ${ }^{1}$ Sometime around the year 2020 , for the first time ever, the number of people aged 65 and older in the world is expected to exceed that of children under the age of $5 .^{1}$

Ageing in Bangladesh is a recent phenomenon. Though internationally accepted cut of age is 65 years, above which peoples are considered elderly, in Bangladesh, persons with age of 60 or above are cited as geriatric age group in different literatures. However, in reality people in this country become older before the age of 60 because of poverty, physical hard working and, inability and illness due to malnutrition and geographical condition as well. Population trends in Bangladesh show that Bangladesh is well into third phase of demographic transition, having shifted from a high mortality-high fertility regime to a low mortality-low fertility one. In 2007, the number of the elderly people aged 60 and over in this country was 9.41 million and it has increased from 1.94 million in 1951 which is quite phenomenal. ${ }^{2}$ Every year approximately 80,000 new elderly are entered into the group of the older persons. The estimates and projections show that the amount is certain to increase markedly with time. ${ }^{3}$ This trend is expected to accelerate and by 2050 the number of persons aged 60+ are projected to be approximately 40.5 million, which is roughly 6 times higher than what it was in the year $2000 .{ }^{4}$ So it is worth saying that the burden of old age diseases in our low income country will be enormous.

The problem of old age is not merely medical; it is physical, mental, economical and socio-cultural. ${ }^{5} \mathrm{~A}$ cumulative approach is needed to combat the problem which should involve the medical professionals, social workers, political leaders, NGOs and media personals. The western society has become successful to blend the above sectors together. As a result, life expectancy and quality of living of aged people have been improved. The most notable contribution is from medical sector. Though the victory over communicable diseases has been achieved, other non communicable diseases like CVD, IHD, DM, malignancy and neuro-degenerative disorders have become more prevalent in developed countries. To overcome this new situation they have established geriatric medicine department in the hospitals targeting the aged people.

The scenario of Bangladesh concerning the old people is quite frustrating. A full blown geriatric policy in our country yet to be formulated. But this is a matter of hope that a geriatric medicine unit as a wing of medicine department of Dhaka Medical College Hospital has been launched in the late 2014. Now it is the time to flourish this small initiative to a complete geriatric medicine department which will be a great achievement and milestone in the history of medicine in Bangladesh.

After the establishment of geriatric medicine unit in DMCH in 2014, total 158 patients have been admitted till $11^{\text {th }}$ March, 2015. 83 of them are male and the rest 75 are female. Multi morbidity is common. Mortality rate was $5.70 \%$. Patients were treated by supportive care only due to lack of emergency medical facilities. Patients with diseases from every subspecialties of medicine e.g. cardiology, nephrology, neurology, endocrinology, respiratory medicine, gastroenterology, were admitted and treated accordingly. In male patients, the mostly encountered diseases were CVD, HTN, COPD, DM and 
bronchial carcinoma. Female patients were predominantly suffering from DM with its complications and UTI. The mean age of admission was 67.4 years \& the patient with highest age was a 108 years male.

After few months of observation in our geriatric medicine unit, certain difference has been noted between the global geriatric trends and that of Bangladesh. The disease pattern is more or less same but infectious disease is more prevalent here. The management strategy adopted in our unit is also quite similar comparing the developed countries. But the most notable difference is economical rather than medical. In the western society, there is a social security service for old and health insurance policy run by government. They bear all the treatment and rehabilitation cost. In our country, as old people are mostly dependant, ${ }^{6}$ they cannot cope with expensive investigations or treatment. So they often fail to maintain the follow up schedule. As a result they come with more serious complications later on.

Regardless of several limitations, the geriatric medicine unit is running successfully since its initiation. We hope that positive steps from the government and donor organisations towards a geriatric friendly health care system will soon be on the cards. Increase in allocation and change in policy will see a rapidly flourishing discipline. The elderly are the people who have fought for this nation it is time we repay them and should not forget that pretty soon we will also be joining them.

(J Banagladesh Coll Phys Surg 2015; 33: 63-64)

\section{Md.Azizul Kahhar \\ Prof. of Medicine, Dhaka Medical College}

\section{Reference:}

1. United Nations Population Division, World population ageing 2009.

2. BBS. Report on Sample Vital Registration System, 20052006, Ministry of Planning, Government of the People's Republic of Bangladesh, Dhaka. 2007.

3. Abedin, Samad. Population Ageing in Bangladesh: Issues and Perspectives. Summary of Country paper, ESCAP Asian Population studies. 1996.

4. United Nations. World Population Prospects: The 2004 revision population database, Population Division, New York. 2005.

5. Haque, Alam. Health Problems of Geriatric People: A Community Based study in a Rural Area in Bangladesh. The Journal of Teachers Association of RMC, Rajshahi 2007.

6. Uddin MT, Hossain IM, Akhtar T. The elderly care services and their current situation in Bangladesh: An understanding from theoretical perspective. J. Med. Sci., 6:131-38. 2006. 